\title{
The views of older people and carers on participation in clinical trials: the PREDICT Study
}

Clin. Invest. (2012) 2(3), 327-336

Concern over the inappropriate exclusion of older people from clinical trials is longstanding. The PREDICT study used mixed methods to investigate the extent of this exclusion and to explore the views of those directly involved. This paper reports findings from that aspect of the study investigating the views of older people and carers. Drawing on findings from earlier stages in the study, a structured interview schedule was developed to form the basis of focus group discussions. Groups were held across nine countries: the Czech Republic, Israel, Italy, Lithuania, Holland, Poland, Romania, Spain and the UK $(n=42)$. Discussants were those living with conditions commonly affecting older people: hypertension, cancer, dementia, heart failure, stroke and depression $(n=285)$. Data were analyzed for differences and commonalities within and between groups. Issues raised fell into four themes: ageism, both within society and amongst clinicians and researchers; advantages and disadvantages to participation; the relationship between the participant and their clinician/research team; and practical features to support participation. Findings confirm that older people and carers see chronological age as an insufficient reason for exclusion from trials and view such exclusion as age discrimination. They point to the complex relationship between healthcare professionals and trial participants and identify the need for cultural and generational sensitivity in trial design, as well as the importance of considering adaptations to meet special needs. Finally, they identify the need for quality of life to be included as an outcome measure in such research and emphasize the importance of including lay perspectives in health research design generally.

Keywords: ageism • charter • clinical trials $•$ consent $•$ ethics $•$ lay perspectives - mixed methods • older people • outcomes • participation

There has long been concern over the inappropriate exclusion of older people from clinical trials in general and the implications for appropriate prescribing of drugs and other treatments. In this paper we present findings from the PREDICT study, exploring the views of older people and carers on such exclusion. The paper begins with a brief exploration of the background evidence on the inappropriate exclusion of older people from clinical trials. It then turns to the PREDICT study and describes the methods employed and outlines findings from the focus groups with older people and carers. Finally, the paper concludes with a discussion of the implications of these findings for both healthcare and research practice as well as for policy.

\section{Background}

Despite the importance of clinical trials in identifying safe and effective therapeutic interventions, there has been widespread evidence over many years that older people have been, and remain, inappropriately excluded from them, with treatment
Bernadette Bartlam ${ }^{\star 1}$, Peter Crome ${ }^{1}$, Frank Lally ${ }^{1}$, Andrew D Beswick $^{2}$, Antonio Cherubini ${ }^{3}$, A Mark Clarfield ${ }^{4}$, David Edbrooke ${ }^{5}$, Albert Farré, ${ }^{6}$ Cees Hertogh ${ }^{7}$, Vita Lesauskaite ${ }^{8}$, Gary Mills ${ }^{5}$, Martin Muller ${ }^{7}$, Jaquim Oristrell ${ }^{9}$, Gabriel I Prada $^{10}$, Carmelinda Ruggiero ${ }^{3}$, Judith Sinclair-Cohen ${ }^{5}$, Katarzyna Szczerbińska ${ }^{11}$, Eva Topinkova ${ }^{12}$ \& Zbigniew Zalewski ${ }^{11}$

${ }^{1}$ School of Medicine \& Research Institute for Social Sciences, Keele University, Keele, UK ${ }^{2}$ Musculoskeletal Research Unit, School of Clinical Sciences, University of Bristol, Bristol, UK

${ }^{3}$ Department of Clinical \& Experimental Medicine, University of Perugia Medical School, Italy ${ }^{4}$ Department of Geriatrics, Soroka Hospital \& the Faculty of Health Sciences, Ben-Gurion University of the Negev, Beer-sheva, Israel

${ }^{5}$ Medical Economics \& Research Centre Sheffield, Rotherham General Hospital, Rotherham, UK ${ }^{6}$ Department de Psicologia Social, Universitat Autònoma de Barcelona, Spain

${ }^{7}$ Department of Nursing Home Medicine,

EMGO Institute for Health \& Care Research,

VU University Medical Center, Holland

${ }^{8}$ Geriatric Clinic, Kaunas University of Medicine,

Kaunas, Lithuania

${ }^{9}$ Department of Internal Medicine \& Geriatrics, Universitat Autònoma de Barcelona, Hospital de Sabadell, Corporació Parc Taulí, Spain

${ }^{10}$ Ana Aslan National Institute of Geriatrics \&

Gerontology, Bucharest, Romania

${ }^{11}$ Institute of Public Health, Jagiellonian University Medical College, Krakow, Poland

${ }^{12}$ Department of Geriatrics, Charles University,

Prague, Czech Republic

*Author for correspondence:

Tel.: 01782733939

E-mail: b.bartlam@med.keele.ac.uk

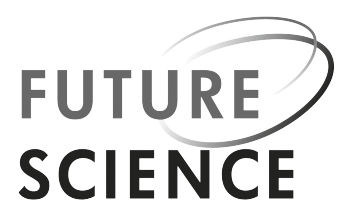
fsg 
recommendations being extrapolated from results of research involving younger populations [1-8]. The situation extends across the range of conditions most commonly affecting older people, including cancer [9], Parkinson's disease [10], sepsis [11] and heart failure [12]. Such exclusion leaves professionals with a difficult decision: either they do not prescribe because of the lack of age-appropriate data or they prescribe despite its lack [4]. Either way, it makes safe, effective prescribing of interventions for older people problematic to say the least, with consequent health and financial cost implications for both the individual and the community [13]. This situation is further complicated by the fact that older people often experience more than one condition at the same time and therefore may be prescribed a number of drugs or treatments simultaneously [13,14]. It is not surprising then, that inappropriate prescribing (IP), which is preventable, has been highlighted as a common and serious global healthcare problem amongst older people, leading to increased risk of adverse drug reactions (ADRs); with polypharmacy being the main risk factor for both IP and ADRs [15]. Against this background of obvious individual patient and societal cost-benefit, the persistent exclusion of older people from clinical trials is perplexing. It becomes yet more so in the face of increasing awareness of the dramatic ageing of our populations: in the last 30 years the number of people in the world aged 60 years or older - the United Nation's definition of an older person [16] - has doubled from 378 million in 1980 to 759 million in 2010. It is projected to more than double again in the next 40 years, rising to two billion by 2050, when older people will outnumber children - those 14 years and younger - for the first time in human history [101]. There are currently 164 million older people in Europe and life expectancy is increasing across all European countries [17]. Alongside this dramatic shift in demography, we know that the burden

\section{Table 1. Type and number of focus groups} conducted.

\begin{tabular}{|ll|}
\hline Patient group & Number of groups \\
\hline Cancer & 7 \\
\hline Cerebrovascular disease & 6 \\
\hline Dementia & 4 \\
\hline Depression & 5 \\
Diabetes & 1 \\
\hline Heart failure & 7 \\
Cerebrovascular disease carers & 3 \\
\hline Dementia carers & 4 \\
\hline Nonspecific carers & 5 \\
\hline Total & 42 \\
\hline
\end{tabular}

of disease is higher in older populations and, since they outnumber men, higher again amongst older women.

\section{Purpose of the study}

In the face of the concerns outlined above, the PREDICT study was established to investigate the extent of this exclusion and to explore the views of those directly involved. The study used a mixed methods approach [18-20] to investigate the issue across nine EU partner countries: the Czech Republic, Israel, Italy, Lithuania, Holland, Poland, Romania, Spain and the UK. Funded under the EU's 7th Framework, the research program was organized into a series of work packages (WPs), sequentially drawing on preceding methods and findings [19]: WP1.1 provided the initial work involving a systematic review of the literature on the representation of older people in clinical trials [21], with a subsection, WP1.2, specifically examining exclusion in ongoing clinical trials in heart failure [12]; WP2 then undertook a survey of the opinions of healthcare professionals [22]. Building on the findings from WPs1, 1.1 and 2, the research questions in WP3 were designed to understand older people's, and their informal carers' views on whether or not they should be included in clinical trials. More specifically, they sought to explore whether there were particular conditions under which they should or should not be invited to participate, whether there were any identifiable barriers or facilitators to such participation and whether people felt that any additional guidelines or legislation were necessary to support appropriate inclusion.

\section{Design \& methods}

A qualitative approach was adopted, employing a structured focus group method. This method allows for the exploration of a tightly defined topic by individuals involved in a particular situation and is suitable for topics that are not considered sensitive or deeply personal. It also allows for the co-construction of meaning, encouraging exploration and debate within the group and is particularly suited to accessing lay knowledge [23].

\section{- Participants}

Discussants were drawn from those groups living with some of the conditions most commonly affecting older people, as well as informal carers. It should be noted that, as was to be expected, participants often had comorbidity. Ages, including those of carers, ranged from 60 to 87 years and a total of 42 focus groups were held. Table 1 indicates the focus groups that were reported on by partners.

\section{- Recruitment}

Recruitment took place through existing patient groups in hospital settings and via community organizations 
working with older people. Only those considered able to give consent were invited to take part. Standardized information letters and consent forms were designed and were sent in advance to individuals as part of the invitation to participate. Groups consisted of between four and 12 participants, of whom 95 were men and 190 women $(n=285$; Figure 1$)$. This ratio was not designed but its emergence comes as no surprise since it reflects the gender-split amongst older populations throughout Europe [24].

\section{- Method}

The interview schedule for the focus groups was structured around the research questions outlined earlier, which, as mentioned, had been identified through the findings from WP1, 1.1 and $2[18,19]$. To assist in standardization across the partners, a video and protocol were produced detailing how to organize and run a focus group [102].

The groups, which took place in the native language of each partner country, had two facilitators. Discussions lasted approximately an hour and began with the written information on the study being explained orally. Discussants were invited to sign the consent forms, if they had not already done so, and consent was again checked at the end of the discussion. To maintain anonymity, discussants were allocated an alphabetic letter that replaced all names within the transcripts and identifying information was stored separately to transcripts. The study was approved by local research ethics committees or equivalents in the Czech Republic, Israel, Poland, Spain, Italy and the UK. National regulations and ethical guidelines determined that research ethics or institutional review was not required in Lithuania, Holland and Romania. A lay summary outlining findings was sent to discussants on completion of the project.

A pilot focus group was held in each country to validate the interview schedule $(n=9)$. It was clear that the majority of people did not understand the notion of a clinical trial and some time was spent in explaining the term before the pilot discussions could begin. A standardized lay explanation was therefore developed for inclusion as part of the information letter and the introductory section of the interview schedule. Piloting resulted in no other changes and so those group discussions have been included in the analysis.

\section{- Analysis}

All focus groups were audio recorded and transcribed. Analysis took place at a number of discrete levels: a researcher from each partner country analyzed their data with a specific focus on the research questions as outlined in the interview schedule [23]. A search

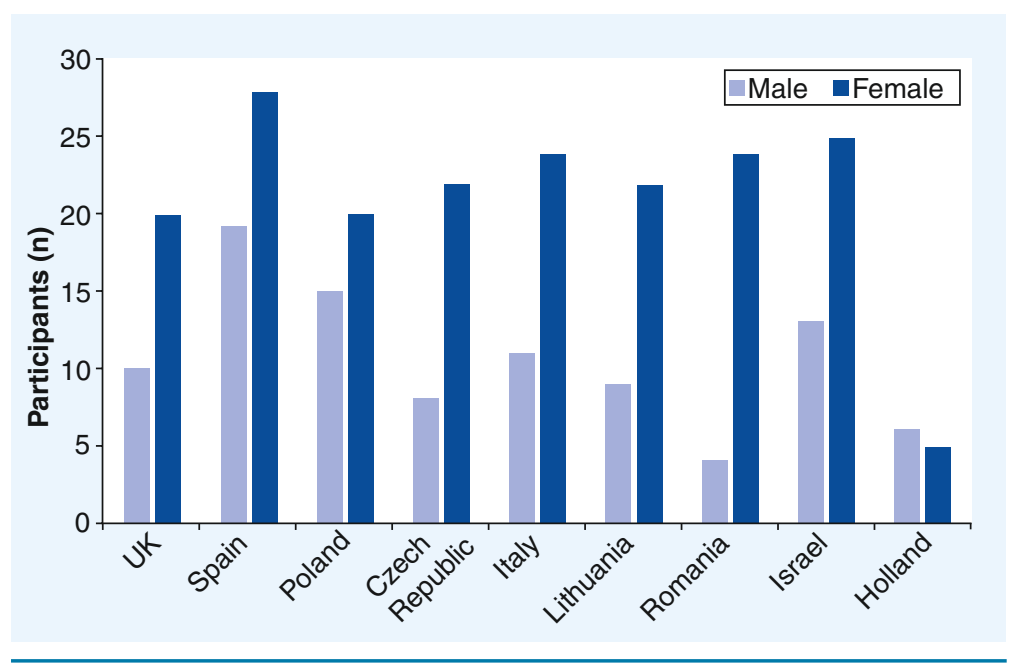

Figure 1. Breakdown of gender for focus groups conducted in all partner countries.

was then performed for confirmatory or challenging evidence across and within all data sets. In keeping with the nature of qualitative and exploratory research, the intention was to develop insights that would hold theoretical representativeness, rather than being based on statistical similarity, that is to say, findings that would be sufficiently general as to hold in other contexts similar to the one under investigation [25]. Once complete, a summary of findings was sent to the lead partner (Keele University, UK) for inclusion in the final analysis. The UK transcripts were used as the starting point for this overarching analysis. As codes emerged from these data, the data from other partners were then checked for additional confirmatory or challenging evidence within and between groups, and between countries in line with basic principles of qualitative data analysis [26].

\section{Results}

The emergent findings fell into four themes: ageism in society generally and amongst clinicians and researchers specifically, awareness of advantages and disadvantages to participation, the relationship between the participant and their clinician/research and practical features to support participation. More than one quote is used where slightly different dimensions to an issue emerged and the quotations chosen are those that best illustrate and summarize common responses.

\section{- Ageism}

Ageism emerged as an overarching theme throughout the discussions and exclusion was seen as linked to the ways in which older people are valued and respected more generally in society: 
- "After a certain age, adult and young people start to neglect or leave us aside" (Depression Group, Italy);

- "And let there be a general principle that old man is still a man" (Cancer Group, Poland).

The majority of discussants felt exclusion was ageist and an infringement of rights:

- “One thing I would say ... they're discriminating against older people in clinical trials and that, where it's appropriate, they should be included" (Dementia Carers Group, UK);

- "Medical research is for everybody. There is no difference between a young adult and a centenarian; they are both persons with same rights" (Stroke Group, Italy).

Unsurprisingly then, age per se was generally not seen as a barrier:

- "I think that the people that take part in the clinical trial should be those for which it is thought that the medicine will be useful ... Age should never be a factor in itself" (Dementia Carers Group, Spain);

- "But there are 90 year-olds that could easily get involved with a trial. I know a lady of 99 and I wouldn't argue with her because she'd win over me any time!” (Dementia Carers Group, UK).

Yet, for others in the same group age clearly was, if not a barrier, at least sufficient reason to decline, highlighting the need for choice on whether or not to participate:

- "My mum and dad wouldn't ... they're in their nineties, so I agree with them to be honest. They're in their nineties, leave them alone" (Dementia Carers Group, UK).

Discussants were very aware of the shift in demography and the importance of taking this into account in generating good science. Indeed, the fact that older people can be excluded from trials produced a surprised response:

- "But these medications are meant for old people, they can't test them on 20-year olds!" (Pilot Group, Poland).

However, an underlying sense of ageism amongst discussants themselves was also evident:

- "It is not so important for us - it is more important to attempt for the grandchildren, for the future generations" (Hypertension Group, Lithuania);

- "There is no point in investing research money in old people; it is preferable to invest in younger people" (Depression Group, Israel).
Or yet more starkly:

- "Elderly people soon die; therefore you cannot make a big harm” (Diabetes Group, Czech Republic).

Discussants appeared very aware that the ageing process affects how an individual will respond to different drugs or therapies and that diversity amongst the older population needs to be taken into account in sampling:

- "A body at 40-years old reacts in a certain way to a drug, at 60-years old the body has another reaction and at 80-years old or above, another one" (Pilot Group, Romania).

Discussants generally perceived increased morbidity and polypharmacy as a clear reason for inclusion:

- "As we get older, we are prescribed more and more drugs ... I mean, I have so many I rattle! It's awful, you know, and I just wonder whether there's enough research gone into what we are given and why, and the effects of the combinations..." (Stroke Group, $\mathrm{UK})$;

- "Older persons use the majority of drugs. It is a paradox that persons who usually take more medicines are excluded from clinical trials investigating such medicines" (Cancer Group, Italy).

\section{- Advantages \& disadvantages to participation}

Participation was not seen as without risk and caution was deemed necessary in cases of frailty where the health of the individual was so poor, such that any additional burden might have negative effect:

- "Well, being older and having more diseases and entering a trial with a drug, you cannot be sure on the body's reactions. Take, for example, the heart, now you can be ok and the next second you close your eyes. Your blood pressure may increase, or you may have a stroke" (Pilot Group, Romania).

Linked to this was concern that participating in research such as trials might disrupt existing, effective coping and management strategies, and also that outcome measures focused simply on extending life years were insufficient reason to take part:

- "I would not participate in a clinical trial and I wouldn't allow that a relative of mine would be given medicine, if it's only to prolong life..." (Dementia Carers Group, Spain);

- "I mean, it is improving this part of life ... It's the possibility of improving that, you know, so that people can make the most of that additional life that is coming really, which is important" (Carers Group, $\mathrm{UK})$. 
Nonetheless, risk was also seen as unavoidable:

- "I think that without risk nothing can be done in this matter" (Dementia Group, Poland).

Motivating factors to becoming involved fell into two categories; benefits to others and to oneself, of which the former appeared dominant:

- "In the short run the profit is not mine personally, in the long run the profit is to the general population" (Pilot Group, Israel);

- "Because it's a beautiful thing if you can help others in their grave diseases" (Cancer Group, Poland).

For others, participating in clinical trials could offer a degree of hope for oneself, including possible improvements in quality of life:

- "I hope that this thing may eventually help me" (Cancer Group, Poland);

- "Researchers can help us to have a good life in spite of the diseases we are affected from" (Stroke Group, Italy).

\section{- Consent \& relationship with clinician/research team}

First amongst those processes that could mitigate risks to participation was the reliability of the person suggesting inclusion, almost invariably seen ideally as a physician:

- "It must be said by a physician I visit regularly ... Then I would like to agree, because my physician tells me this" (Depression Group, Poland);

- "I believe the doctor. He simply wants what is good for me" (Pilot Group, Israel).

This relationship between the potential participant and the person issuing the invitation to take part was seen as so crucial that being approached cold was not considered generally acceptable:

- "I was sent some literature, I think it was probably just one of these 'drops', about whether I'd like to take part in bowel cancer trials, would I send samples and I declined the offer because ... it didn't come from a doctor's referral" (Pilot Group, UK).

For the vast majority the relationship extended to management of the clinical trial itself:

- "[The person] who carries out the clinical trial should be a physician so that I can have confidence in him" (Heart Failure Group, Poland);

- "Through direct communication with the physician who follows you in this trial you feel protected" (Pilot Group, Romania).
This emphasis on the role of the physician was tied to issues of safety and the importance of close scrutiny in both monitoring trials generally and the overall health of individual participants:

- "I am for testing drugs but it must be under the highest clinical control" (Cancer Group, Poland);

- "Public institutions and universities should lead medical research, then private drug companies can be involved but they should remain under supervision" (Carers Group, Italy).

Discussants were very aware that the final decision on whether or not to take part must remain with the individual, or if that was not possible, with their family:

- "Only in such a situation it is the family who must decide whether to include an infirm person, one that is unaware, in clinical tests ... no medication must be given without consent" (Pilot Group, Poland).

Crucial to consent was clear information:

- "As for the question you asked me, whether I would agree to take part in a clinical trial, I think I would, as long as there was information behind it" (Dementia Carers Group, Spain).

It was felt that information was not always available in an accessible form:

- "But generally those leaflets are written in a very sophisticated, specialist language ... and when a patient finished two grades of a primary school will he understand a lot of that?" (Pilot Group, Poland).

The importance of ongoing explanations was also emphasized:

- "Doctors are not explaining, every time" (Cancer Group, Lithuania);

- "You take part in it, but you don't even know how this investigation is developing. You don't know if it's going somewhere or not" (Cerebrovascular Carers Group, Spain).

The discussion on information also included references to the lack of feedback some felt they received about the outcomes of research they did take part in, as one of the few people to have experience of a clinical trial pointed out:

- "I really would like to know the results of clinical trials in which my relatives were involved, but nobody told me anything" (Carers Group, Italy).

At a broader information level, greater public awareness of the importance of trials was advocated as a way of increasing participation: 
- "If older persons become more aware of the problem, they will get involved more easily" (Depression Group, Italy).

\section{- Practical aspects to participation}

Discussants also identified some practical issues in being able to participate:

- "Well, I cannot go because I am very old. If I had someone to bring me and take me from there, I can go, for sure" (Pilot Group, Romania).

People were aware that such support would come frequently from families and carers and where they felt that taking part might put additional pressure on carers, they expressed a reluctance to participate. This concern was rooted in reality, as the experience of this Italian carer indicates:

- "The participation was really hard work. I had to give one more pill every day - he was already taking several pills - and write notes on them every day. It lasted 1.5 years and every 3 months I had to bring him to the follow-up visit. Each visit was really extensive, lasted long and included an ECG" (Carers Group, Italy).

These difficulties could be further heightened when carers themselves were in poor health:

- "My only problem as a carer is that I'm the same age and I'm a walking stroke in that I've got high blood pressure, diabetes and cholesterol" (Carers Group, UK).

The location of the trial was also considered to be an important factor in an individual's capacity to take part, as was access to transport. For the majority of people, as has been seen, having a trial located in a hospital gave an additional sense of security in emphasizing that they would be more closely monitored. However, for others having to travel to participate was seen as a disadvantage:

- “[The researchers] won't do the tests at home, so then they have to go to the laboratory or hospital. That's why I think this would be a problem" (Pilot Group, Spain);

- "Often, older persons have walking difficulties and are not able to reach the research centers or the hospitals" (Cancer Group, Italy).

\section{- Legislation $\&$ the role of a charter}

Greatest diversity in opinion was expressed in responses to the question of whether legislation would help in supporting participation. Some were positive:

- "Only that I think it is important that they are regulated and that they have guidelines, because there are people, the drug companies, with vested interests, aren't there?" (Carers Group, UK).

Yet it was also considered to be so evidently sensible, and in the interests of good science, to include older people, that there ought to be no need for legislation:

- "I don't think that they have to create a similar law so older people can participate" (Dementia Carers Group, Spain);

- "What I feel is that the people who are doing the research in the first place, why have they got to have a government regulation ... it seems like ordinary brain common sense to include a whole range" (Dementia Carers Group, UK).

In addition, there was also feeling that existing regulation should be sufficient:

- "We're already covered under the Age Discrimination Act” (Depression Group, UK).

The development of a charter was seen as a natural consequence of acknowledging that participation was important and was also linked to increasing public awareness on the issue:

- "It may be useful to write and disseminate a charter. It can help older persons to be aware about clinical trials and to be informed about medical research" (Stroke Group, Italy).

However, there was some unease about government involvement generally as well as a lack of faith in the ability of a charter to deliver change, again rooted in a heavy emphasis on the relationship with physicians:

- "We have our historical experiences with charters. We do not need to do anything like this. We trust our doctors, our specialists. They lead us till the end" (Pilot Group, Czech Republic).

For some people this distrust of formal frameworks was at a more general and stark level:

- "Nobody follows neither regulations, neither moral norms" (Cancer Group, Lithuania).

\section{Discussion}

- "I think it is important [to include older people], because only then you have the choice whether to participate or not. Now you don't have a choice" (Stroke Group, Holland).

In the light of these findings we now examine what appear to us to be the key policy, practice and research implications. As the context in which the study took 
place, it is necessary to reflect on the vast cultural diversity within Europe. Such diversity goes deep: Europe in the 20th century underwent profound upheaval, economically, politically and socially. The nation states that make up what is now the EU have emerged from this period of immense turmoil with varied experiences, as have those individuals who are aged 60 years and over: some have experienced extreme and prolonged persecution, whilst others have escaped more lightly; some have been able to take advantage of improved employment and health and social care opportunities, others have remained in severe poverty and social exclusion. Moreover, such experiences are age-cohort specific, with the oldest having greater exposure to the intensity of change than the emerging baby-boom generation. This diversity is reflected in a recent survey of 28 nation states, which reported that the average age at which youth is perceived to end varies considerably, from 34 in Sweden to 52 in Greece [17].

Turning to our findings, it was clear that despite the diversity highlighted above, there was a general consensus across all themes. First amongst these was ageism, which was clearly an overarching theme running through all of the discussions. At an individual level, discussants spoke powerfully of experiences of such discrimination in their lives and clearly saw exclusion on age grounds as an infringement of human rights. It is now more than 35 years since Robert Butler's Pulitzer Prize-winning book identified ageism as a prejudice leading to older people facing insufficient pensions, marginal housing and inadequate medical care [27]. Yet discrimination on age grounds still appears rife; in the most recent European Social Survey, 44\% of 58,988 respondents reported it as a very serious or quite serious problem [17]; and a recent UK review of NHS referrals found that a significant number of decisions are based solely on the patient's age, rather than the individual's needs or fitness levels [28]. Such ageism is reflected in the work of Bayer and Tadd, who found that in 155 studies in the UK relevant to older people, more than half had an unjustifiable upper age limit and neither the local nor the multicentered research ethics committees had challenged this [3]. A more recent review suggests that the scale of such discrimination is declining but notes that unjustified age limits remain frequent in the protocols of intervention studies [29]. It has also been pointed out that many clinicians in the USA and Europe have an inherent bias that associates older age with poorer outcomes from participation in trials $[22,30]$. Findings here challenge such negative stereotyping in pointing out that older people themselves consider neither age nor cognitive impairment sufficient reason for exclusion. They do, however, emphasize the need for close monitoring of trial participants, and that improved quality of life - rather than simply extending years - should be amongst the main outcome measures. They also indicate that where an individual may be unable to consent for themselves, those who are next of kin must be involved fully in the decision-making process and retain ultimate authority. However, there was a degree of ageism expressed on the part of discussants themselves, which may be due to the ways in which older people believe the stereotypes they hear about themselves [31], which signals the complexities in addressing this issue. In addition, and again contrary to the views of many professionals, discussants generally perceived increased morbidity and the resulting polypharmacy as clear rationale for inclusion, rather than exclusion. Indeed, members of the UK Dementia Carers Group identified only three areas where older people should not be included in clinical trials; conditions focused on young people, hormone replacement therapy and birth control. Furthermore, with women both outnumbering men demographically and consuming more medicines, exclusion from clinical trials is a highly sexist issue [4].

Second, responsibility and accountability in clinical trials was highlighted by discussants as of key importance and is a major challenge to those commissioning and carrying out research in this field. Trials are commonly conducted by large drug and medical device companies as part of their process of product development. However, as was reflected in concerns expressed in the focus groups, such companies can have very negative public opinion ratings and key to the success or otherwise of a trial are collaborations with clinicians in the field [32]. Such collaboration can lead to powerful conflicts of interests in which the human participants in trials can be greatly disadvantaged. Although one or two discussants voiced disappointment in their relationship with their physician, for the majority of people in the study this was clearly a relationship of great trust, whether with their family doctor or a hospital-based specialist [33]. The trust described by discussants is ethically challenging, particularly in the light of the reliance of patients on the expertise and advice of their physicians [34]. A recent study exploring oncologists' communication strategies in seeking informed consent from patients, identified that they "used persuasive communication, made explicit recommendations, or implicitly expressed a treatment preference and were choice limiting" [35]. Adding to this, misreporting of trial findings, and indeed failure to publish at all in some instances, resulting in delays in generation of knowledge and in certain cases patients suffering and dying unnecessarily, have been identified as significant issues [32]. Even when conducted to the highest standards, adverse affects can be severe, as the recent example of the first-in-man clinical trial of TGN412 (intended to treat rheumatoid 
arthritis, leukemia and multiple sclerosis) showed, where six healthy male volunteers developed multiorgan failure and required critical care [36].

Closely linked to this notion of accountability, concerns were expressed by discussants in relation to legislation and developing a charter, and it is in these discussions that opinions were most divided, perhaps unsurprising given the political history of Europe. One might surmise that previous life experiences of state-led oppression might leave some people with a profound distrust of legislation of any form, yet equally one might suppose that it could generate a more passionate avocation of such frameworks: we cannot say from this work. What is clear is that, whilst formal legislation was not on the whole deemed to be appropriate, it seemed that people generally felt a charter would be useful, not least in raising public awareness of the issue. Indeed, discussants felt that existing laws should be sufficient and that it was the lack of their implementation that should be addressed. In keeping with this, there can be no doubt that the European Convention on Human Rights, first drawn up in 1950, has had a substantial impact on laws throughout Europe. However, as Peter Townsend points out, "justifiable and constitutionally entrenched Acts do not provide a complete answer ... Public officials, rights activists, politicians and individual citizens have to share responsibility for acceptance and institutionalization of rights" [37]. This highlights the still substantial gap between antidiscriminatory legislation and practice, and supports the argument that challenging ageism requires a fundamental paradigm shift, not just at an individual and local level but globally [38].

Third, whilst crucial to the ethical integrity of any research involving human participants, the importance of informed consent in the light of the potential risks often associated with clinical trials is further highlighted. Therefore, it is worrying to note that the extent to which participants do indeed give fully informed consent remains seriously contested [34,35,39-43]. Discussants here highlighted the crucial importance of clear, accessible information as a fundamental prerequisite to consent and participation. Such information needs to be in a variety of formats that can be easily understood by a diverse sample, including those with impaired cognitive function [44] and it should not be assumed that everyone can read, or that they will disclose that fact, or that their grasp of language allows understanding of difficult concepts [45]. To ensure adequate understanding, additional steps should be taken; for example, by discussing the protocol in lay terms and in detail, ensuring an environment where any hearing difficulties will not be magnified, allowing sufficient time for the individual to process details and ask questions and creating an atmosphere where they feel empowered to do so [46]. Again, the language of clinical trials adds a further imperative to such requirements: whilst the term is one that is commonly found in the media, it is in fact a highly complex research method [47]. It was clear from this study that discussants' understandings were generally very limited, reflected in the fact that only ten people across all nine countries self-identified as having experience of trials, either personally or vicariously. Whilst difficulty in understanding could be at the level of education, it could also be more linguistically complex: the Polish for clinical trials, for example, is 'badanie kliniczne', a term which can be itself misleading as it is easily confused with an extensive medical examination or with being selected to receive therapies that are not generally available because of expense. At a yet more profound emotional level, some reservations were expressed amongst discussants who were Holocaust survivors and for whom the term 'clinical research' holds a highly charged, deeply disturbing connotation. All of which again emphasizes the need for information that is sensitive, not only educationally but also culturally and generationally.

Finally, the importance of including lay perspectives in research planning, development and outcome assessment emerged strongly. Fundamental to this - and an important ethical dimension to information giving increasingly recognized in work on user involvement in public services [48] - is giving meaningful feedback to participants about the research in which they have been/are involved. Such feedback is key to embodying anti-ageism principles and challenging the myths that currently constitute the barriers facing the inclusion of older people in clinical trial research. It should be an ongoing part of the research process itself and not just feature - at best - at the conclusion. Another expression of anti-ageist principles and valuing lay engagement lies in the degree to which research seeks to practically facilitate the contribution of older people [49]. In addition to practical issues such as disabled access and support for those with mobility and/or sight and/or hearing difficulties, appropriate transport, and clear information on what to expect at each visit, such measures include account being taken of the needs of carers. This latter is, an issue that cannot be over-emphasized, since placing additional burdens on carers can affect both recruitment and retention, in addition to having potentially adverse affects on the carer themselves [45,50].

\section{Future perspective}

Including older people in the clinical trials of treatments that will be available to them is sound science. As the world's population continues to age the imperative to do so will increase with IP and ADRs carrying a proportionate increase in human and financial costs. Including older people will require increasing attention 
to appropriate communication and support strategies, spanning a range of issues from the content of information and how it is delivered, through to transport and support for carers. Developing clinical trials that have the resources for such inclusion, will require the advice and perspectives of older people themselves.

\section{- Limitations}

Owing to time constraints, it was not possible to have all the transcripts translated in full into the language of the lead institution (English). This inevitably has led to a degree of limitation on the level and detail of analysis possible, which was restricted to simple content analysis and was not linked to individual biographies or sociodemographic circumstances. Linking in such a way and thus providing a life-course context for individual views might yield pertinent results since, as was pointed out earlier, those individuals who lived through the last world war and those who have experienced state oppression, forced migration or discrimination during their lives may have different views on the meanings of community, or on the importance of helping others, than those who have experienced a good quality of life. Alternatively, they may hold the same views but for different reasons: the study has not accessed those nuanced differences, nor was it able to fully account for differences between age cohorts, gender, ethnicity or disability.

The themes that emerged from the study have been incorporated into the European Charter on the Rights of Older People in Clinical Trials [103].

\begin{abstract}
Financial \& competing interests disclosure
The authors have no relevant affiliations or financial involvement with any organization or entity with a financial interest in or financial conflict with the subject matter or materials discussed in the manuscript. This includes employment, consultancies, honoraria, stock ownership or options, expert testimony, grants or patents received or pending, or royalties. No writing assistance was utilized in the production of this manuscript.
\end{abstract}

\section{Executive summary}

- Despite some improvements over the past 10 years, older people frequently remain excluded from clinical trials of various treatments offered to them.

- Such exclusion leads to inappropriate prescribing, which has been highlighted as a common and serious global healthcare problem amongst older people, leading to increased risk of adverse drug reactions.

- Older people and their carers consider age alone to be an insufficient reason for exclusion.

- Users should be included in all stages of a trial, from planning through to evaluation.

- Transparent and appropriate methods for obtaining and maintaining consent amongst diverse populations need to be developed. Such consent measures are closely linked to the accountability of those running trials and to a relationship of trust between participants and trialists, seen as key to facilitating the participation of a wide range of older people.

- Outcome measures should include quality of life and should respect the values of older people.

- Older people have the right to evidence based treatments and exclusion from trials on the basis of age alone is an infringement of human rights.

\section{References}

1 Clarfield AM, Friedman R. A survey of the age structure of 'age relevant' articles in four medical journals. J. Am. Geriatr. Soc. 33, 773-778 (1985).

2 Bugeja G, Kumar A, Banerjee A. Exclusion of elderly people from clinical research: a descriptive study of published reports. $B M J$ 315, 1059 (1997).

3 Bayer A, Tadd W. Unjustified exclusion of elderly people from studies submitted to research ethics committee for approval: descriptive study. BMJ. 321, 992-993 (2000).

4 Godlovitch G. Age discrimination in trials and treatment: old dogs and new tricks. Monash. Bioeth. Rev. 22(3), 66-77 (2003).

5 Kemeny MM, Peterson BL, Kornblith AB et al. Barriers to clinical trial participation by older women with breast cancer. J. Clin. Oncol. 21, 2268-2275 (2003).

6 McMurdo MET, Witham MD, Gillespie ND. Including older people in clinical research. BMJ. 331, 1036-1037 (2005).

7 Habicht DW, Witham MD, McMurdo ME. The under-representation of older people in clinical trials: barriers and potential solutions. J. Nutr. Health Aging 12(3), 194-196 (2008).

8 Cherubini A, Signore SD, Ouslander J, Semla T, Michel JP. Fighting against age discrimination in clinical trials. J. Am. Geriatr. Soc. 58(9), 1791-1796 (2010).

9 Kagan SH. Ageism in cancer care. Semin. Oncol. Nurs. 24(4), 46-253 (2008).

10 Rajapakse A, Rajapakse S, Playfer J. Age bias in clinical trials of Parkinson's disease treatment. J. Am. Geriatr. Soc. 56(12), 2353-2354 (2008).

11 Rajapakse S, Rajapakse A. Age bias in clinical trials in sepsis: how relevant are guidelines to older people? J. Crit. Care. 24(4), 609-613 (2009).

12 Cherubini A, Oristrell J, Pla X et al. The persistent exclusion of older subjects from ongoing clinical trials on heart failure. Arch. Intern. Med. 171(6), 550-556 (2011).

13 Milton JC, Hill-Smith I, Jackson SHD. Prescribing for older people. BMJ 336, 606-609 (2008).

14 Herrera AP, Snipes SA, King DW, TorresVigil I, Goldberg DS, Weinberg AD. Disparate inclusion of older adults in clinical trials: priorities and opportunities for policy and practice change. Am. J. Public Health 100, S105-S112 (2010). 
15 O’Mahony D, Gallagher PF. Inappropriate prescribing in the older population: need for new criteria. Age Ageing 37(2), 138-141 (2008).

16 United Nations: Department of Economic and Social Affairs, Economic Division. World Population Ageing: 1950-2050. (2002).

17 Abrams D, Sophieke Russell P, Vauclair C, Swift H. Ageism in Europe: Findings from the European Social Survey. Ray S, Robinson N (Eds). Age UK, London, UK (2011).

18 Onwuegbuzie AJ, Burke Johnson R, Turner LA. Towards a definition of mixed methods research. Mixed Methods Research 15, 33-56 (2012).

19 Creswell JW, Plano Clark VL. Designing and Conducting Mixed Methods Research. Sage Publications, Thousand Oaks, CA, USA (2007).

20 Bergman MM. Advances in Mixed Methods Research. Sage Publications, Thousand Oaks, CA, USA (2008).

21 Beswick AD, Dieppe P, Burke M et al. Improving representation of older people in clinical trials: a PREDICT systematic review. Eur. J. Public Health. 28(19), 201 (2009).

22 Crome P, Lally P, Cherubini A et al. Exclusion of older people from clinical trials: professional views from nine European countries participating in the PREDICT study. J. Am. Geriatr. Soc. 58, 583-584 (2010).

23 Bryman A. Social Research Methods (3rd Edition). Oxford University Press, Oxford, UK (2008)

24 Peace S, Dittmann-Kohli F, Westerhof GJ, Bond J. The ageing world. In: Ageing in Society: European Perspectives on Gerontology. Bond J, Peace S, Dittmann-Kohli F, Westerhof GJ (Eds). Sage Publications, London, UK, 1-14 (2007).

25 Sim J, Wright C. Research in Health Care: Concepts, Designs and Methods. Nelson Thornes, Cheltenham, UK (2000).

26 Miles MB, Huberman MA. Qualitative Data Analysis: an Expanded Sourcebook. Sage, Thousand Oaks, CA, USA (1994).

27 Butler RN. Why Survive? Being Old in America. Harper and Row, New York, NY, USA (1975).

28 Scott G. Ageism is rife in health care. Nurs. Stand. 25(27), 1 (2011).
29 Cruz-Jentoft A, Gutiérrez B. Upper age limits in studies submitted to a research ethics committee. Aging Clin. Exp. Res. 22(2), 175-178 (2010).

30 Siu LL. Clinical trials in the elderly - a concept comes of age. N. Engl. J. Med. 356(15), 1575-1576 (2007).

31 Bennett T, Gaines G. Believing what you hear: the impact of aging stereotypes upon the old. Educ. Geront. 36(5), 435-445 (2010).

32 Dickersin K, Chalmers I. Recognising, investigating and dealing with incomplete and biased reporting of clinical research: from Francis Bacon to the World Health Organisation. J. R. Soc. Med. 104(12), 532-538 (2010).

33 Townsley CA, Chan KK, Pond GR, Marquez C, Siu LL, Straus SE. Understanding the attitudes of the elderly towards enrolment into cancer clinical trials. BMC Cancer 6, 34, (2006).

34 Corrigan O. Empty ethics: the problem with informed consent. Sociol. Health Illn. 25(7), 768-792 (2003).

35 Brown R, Bylund CL, Siminoff LA, Slovin SF. Seeking informed consent to Phase I cancer clinical trials: identifying oncologists' communication strategies. Psycho. Oncol. 20(4), 361-368 (2011).

36 Department of Health. Expert Scientific Group On Phase One Clinical Trials: Final Report. Her Majesty's Stationary Office, Norwich, UK (2006).

37 Townsend P. Using human rights to defeat ageism: dealing with policy-induced 'structured dependency'. In: Critical Perspectives on Ageing Societies. Bernard M, Scharf T (Eds). Policy Press, Brisol, UK, 27-46 (2007).

38 Tang K. Taking older people's rights seriously: the role of international law. J. Aging Soc. Pol. 20(1), 99-117 (2008).

39 Barron JS, Duffey PL, Byrd LJ, Campbell R, Ferrucci L. Informed consent for research participation in frail older persons. Aging Clin. Exp. Res. 16(1), 79-85 (2004).

40 Banja JD, Dunlop B. Enhancing informed consent in clinical trials and exploring resistances to disclosing adverse clinical trial results. Am. J. Bioethics 9 (8), 39-41 (2009).

41 Lema VM, Mbondo M, Kamau EM. Informed consent for clinical trials: a review. East Afr. Med. J. 86(3), 133-142 (2009).
42 Hereu P, Pérez E, Fuentes I, Vidal X, Suñé P, Arnau JM. Consent in clinical trials: what do patients know? Contemp. Clin. Trials 31(5), 443-446 (2010).

43 Behrendt C, Gölz T, Roesler C, Bertz H, Wünsch A. What do our patients understand about their trial participation? Assessing patients' understanding of their informed consent consultation about randomised clinical trials. J. Med. Ethics 37(2), 74-80 (2011).

44 Jeste DV, Barton WP, Golshan S et al. Multimedia consent for research in people with schizophrenia and normal subjects: a randomized controlled trial. Schizophr. Bull. 35(4), 719-729 (2009).

45 Scharf T, Bartlam B, Hislop J, Bernard M, Dunning A, Sim J. Necessities of Life: Older People's Experiences of Poverty. Help the Aged, London, UK (2006).

46 Fearn P, Avenell A, McCann S, Milne AC, Maclennan G, MAVIS trial group. Factors influencing the participation of older people in clinical trials - data analysis from the MAVIS trial. J. Nutr. Health Aging. 14(1), 51-56 (2010)

47 Peace KE, Chen D. Clinical Trial Methodology. Chapman \& Hall, London, UK (2010).

48 Scourfield P, Birch S. Ethical considerations when involving older people in public service participation processes. Ethics Soc. Welfr. 4(3), 236-253 (2010).

49 Scharf T, Bartlam B. Ageing and social exclusion in rural communities. In: Rural Ageing: A Good Place to Grow Old? Keating N (Ed.). Policy Press, Bristol, UK, 97-108 (2008).

50 Phillips J, Bernard M, Chittenden M. Juggling Work and Care: The Experience of Working Carers of Older Adults. Policy Press, Bristol, UK (2002).

\section{Websites}

101 United Nations. World Population Prospects, Revision (2008). www. social.un.org/index/Ageing/ DataonOlderPersons.aspx

102 PREDICT study: how to run a focus group. www.keele.ac.uk/csg/downloads

103 PREDICT. European Charter on the Rights of Older People in Clinical Trials. www.predicteu.com 